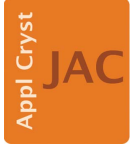

JOURNAL OF

APPLIED

CRYSTALLOGRAPHY

ISSN 1600-5767

\section{Recent Advances in the Scientific Research on Ancient Glass and Glaze. Edited by Qinghui Li and Julian Henderson. World Scientific, 2016. Pp. 572. ISBN 978-981-4630-28-3. Price GBP 43.00 (softcover).}

\author{
Gilberto Artioli* \\ Dipartimento di Geoscienze - Centro CIRCe, Università di Padova, Via Gradenigo 6, I-35131 Padova, Italy. \\ *Correspondence e-mail: gilberto.artioli@unipd.it
}

The volume on Recent advances in the scientific research on ancient glass and glaze collects the papers presented at the second International Workshop on Archaeology of Glass, held in Shanghai on 12-14 November 2012, supplemented by a few additional papers especially prepared for the volume. It is a welcome addition to a series of books mainly focused on ancient Asian glass research, which were published as proceedings of the previous International Workshops/Symposia on Glass held in Beijing (1984) and Urumqi/Shanghai (2004/2005). The two existing volumes (Brill \& Martin, 1991; Gan et al., 2009) indeed served brilliantly as primary references for the scientific investigation of Asian glass materials. The material and the data presented in this newly published book are also bound to be important for scholars and researchers in the field. Virtually everybody interested in ancient Asian glass will benefit from the updated archaeological and archaeometric information.

The first part of the book has an essentially archaeometric character, and the chapters include descriptions and photographs of samples and materials, besides a wealth of data resulting from textural, chemical and isotopic analyses. Chapters 1-11 may be profitably consulted as summaries of the existing knowledge concerning ancient Chinese glass and faience (Chapter 1), together with welcome updates on recent archaeological finds and scientific characterization. Several papers focus on archaeological glass materials from sites along the broadly defined Silk Road, in the attempt to reconstruct the diffusion of glass imports and the historical evolution of technical and manufacturing skills. I found the chapters on maritime exchanges (Chapter 3) and on the chemical distinction and geographical diffusion of potash glass in Southeast Asia (Chapter 5) especially clear and informative, the latter reaffirming the missing evidence for the potash glass production sites. Most of the other chapters in this archaeometric part of the volume (amounting to some 230 pages) deal with specific Asian case studies: the diffusion of Islamic glasses (Chapter 2), Japanese Kofun glass beads (Chapter 4), Han Dynasty chimes (Chapter 6), Heian period temple glass (Chapter 7) and several important Chinese sites, including the Famen Temple (Chapters 8-10). Within this Asian context the chapter on Byzantine glass supply in Dichin, Bulgaria (Chapter 11), seems a little out of place, even though it thoroughly describes a very interesting case of glass use and consumption. Overall, this first block of 11 chapters provide a useful overview of current research in Asian glass. It is intriguing to note the overwhelming use of data resulting from portable X-ray fluorescence (pXRF) measurements, whose significance has been highly debated because of limited penetration, absorption and surface effects. The great success of pXRF applications in China and Japan is clearly the result of the efforts of Professor Nakai in collaboration with Ourstex. The instrumentation developed in Tokyo, encompassing careful calibration and measurements under vacuum conditions, has been evidently reapplied in Shanghai with remarkable success. Readers interested in instrumental details will find in Chapter 14 a very interesting discussion on the significance of chemical data obtained with different measurement techniques.

The second part of the book (amounting to about 315 pages) deals with problems mostly related to glass technology. A number of characterization techniques, encompassing advanced imaging measurements such as optical coherence tomography (Chapter 21) and synchrotron computed micro-tomography (Chapter 26), have been applied to 
investigate microstructural and textural issues related to the interpretation of manufacturing processes. The presented case studies include early pottery glazing (Chapters 15 and 19-21), the ancient making of fine porcelains and celadons (Chapters 16-17), and the fascinating issues related to production of Chinese blue and Chinese purple materials (Chapters 23-25), which are the $\mathrm{Ba}, \mathrm{Cu}$-based silicate phases representing the Asian version of Egyptian blue (cuprorivaite). Other contributions deal with glass corrosion (Chapter 12), the Raman characterization of glassy matrices (Chapter 13) and the use of $\mathrm{Sr}$ isotopes to pinpoint fluxing agents in high fired glazes (Chapter 18). The chapter on natural glass materials (obsidian, tektites; Chapter 27) provides a short summary of the composition of volcanic and meteoric glasses, though I found it a little out of context.

In general, the format and style of the book make it easy to read and peruse, although a more careful proofread of this English version would have been appreciated, since a large number of misprints, some mistaken figures (for example Fig. 5.3 duplicating the PKT diagram and missing the KSK one) and several poorly legible graphs are present in print.
Further, as a nonspecialist in the field I would have enjoyed seeing better maps of the cited archaeological sites and routes, maybe inserting a few summarizing maps as appendices. Certainly the general reader would greatly appreciate a short synopsis of Chinese dynasties and Japanese archaeological chronology. A diagram inserting the numerous historical and archaeological periods into a consistent timeline would greatly help the comprehension of the text for the non-aficionado.

Even so, it must be acknowledged that the large amount of information provided in the form of fresh chemical and isotopic data and archaeological updates largely overrides these minor formal flaws. The book represents a valuable reference and an essential compendium of modern Asian glass research.

\section{References}

Brill, R. H. \& Martin, J. H. (1991). Editors. Scientific Research in Early Chinese Glass. New York: The Corning Museum of Glass. Gan, F. X., Brill, R. H. \& Tian, S. Y. (2009). Ancient Glass Research Along the Silk Road. Singapore: World Scientific Publishing. 